\title{
"Sátira gramatical” y emancipación: la figura del profesor de latín en la obra de Fernández de Lizardi
}

\author{
'Grammatical Satire' and Emancipation:
}

The Professor of Latin at Lizardi's Work

\author{
Javier ESPINO MARTÍN \\ Grupo de Historiografía Literaria \\ (Universidad Complutense de Madrid) \\ Universidad Nacional Autónoma de México \\ condotiericda@yahoo.es
}

RESUMEN: En este trabajo se pretende analizar fundamentalmente el papel que desarrolla la "sátira gramatical", como subgénero literario y su aplicación en la figura del "profesor de latín" dentro de las novelas picarescas del escritor mexicano José Joaquín Fernández de Lizardi. Estas novelas son: El Periquillo Sarniento (1816 y 1830) y su continuadora Vida y hechos del famoso caballero D. Catrín de la Fachenda (publicada póstumamente en 1832). En la elaboración de este artículo hemos partido, primero, de la definición del concepto de "sátira gramatical", que conlleva la "carnavalización" irónica del preceptor al aplicar la enseñanza de la gramática latina. Seguidamente, hemos ilustrado estos conceptos con los "dómines" que aparecen en relevantes autores literarios y que sirvieron de modelo para la configuración del "profesor de latín" en la obra de Lizardi. Según eso, hemos situado las novelas del mexicano en su contexto sociocultural y hemos analizado la función que el subgénero de la sátira gramatical, así como la figura y método educativo del profesor de latinidad desempeña en sus novelas, con el objetivo fundamental de impulsar el espíritu emancipador de México respecto a la Corona española.

ABSTRACT: This paper aims to analyze the role played by grammatical satire and the figure of the "Latin teacher" within the Mexican picaresque novels by José Joaquín Fernández de Lizardi (The Periquillo Sarniento - 1816 and 1830 - and its successor Life and Deeds of the Famous Knight Don Catrin de la Fachenda, published posthumously in 1832). In preparing this article, we start from the definition of "gramatical satire", which involves an ironic "carnivalization" of he who teaches Latin grammar. Next, we illustrate these concepts with the "schoolmasters" appearing in relevant literary authors that served as a model for the character of the Latin teacher in Lizardian works. According to this, we locate Lizardi's novels in their socio-cultural context and we analyze the role that both gramatical satire and the figure of the Latin teacher and his teaching method played in promoting a Mexican emancipatory attitude in regards to the Spanish Crown.

PALABRAS CLAVE: sátira gramatical, dómine, emancipación, novela picaresca mexicana.

KEYWORDS: grammatical satire, domine, emancipation, Mexican picaresque novel.

ReCiBIDO: 12 de abril de 2013 - ACEPTADO: 1 de mayo de 2013. 


\section{Definición de la "sátira gramatical" y su recorrido literario}

La "sátira gramatical" se trata de una modalidad de la sátira convencional, cuyos rasgos específicos se desarrollan en el propio género satírico, o bien en otros géneros literarios mayores como la novela (en especial, picaresca o autobiográfica), el teatro, o la lírica. La sátira gramatical no tiene rasgos específicos, ni características fijas ni teóricas, aunque se identifica principalmente por exponer una crítica literaria contra la mala enseñanza de las lenguas, especialmente la latina, a través de la figura del pedante, o del que enseña mal, el comúnmente llamado dómine. Según esto, este subgénero satírico se suele estructurar mediante dos directrices básicas: retrato irónico y caricaturesco del maestro de latinidad, y exposición de una pedagogía que se caracteriza por su ridiculez y extravagancia, lo que perjudica gravemente la sólida formación en la materia. El método educativo de los dómines se suele desglosar, a su vez, en dos grandes partes: por un lado, la enseñanza de la gramática, el Arte de Nebrija, que se ve complementado con "manualillos" que lo saturan de reglas y excepciones y que hacen que el aprendizaje se base en la memorización de reglas, innecesarias y absurdas que acaban deformando la propia lengua de partida. Por otro lado, está el aprendizaje de autores que ilustran la latinidad: para ello, normalmente, evitan a todo autor puro y elegante de la talla de Horacio, Cicerón, César, Salustio, etcétera, y prefieren a escritores farragosos, con un latín oscuro y abigarrado, como Valerio Máximo, Estacio, o bien el latín eclesiástico de los Padres de la Iglesia, de los catecismos, o del concilio de la Iglesia contrarreformista.

Si uno de los elementos básicos de la sátira gramatical es el método educativo, el otro, como ya hemos apuntado, es la figura "carnavalesca" del propio maestro de latinidad. Expliquemos en qué consiste. Según preconizaba el crítico ruso Mijail Bajtín, ${ }^{1}$ la risa carnavalesca se dio en los géneros literarios y en manifestaciones lúdico-festivas de la Edad

\footnotetext{
${ }^{1}$ Bajtín ha estudiado la risa carnavalesca especialmente en la obra de Rabelais, y llega a las siguientes conclusiones: "Ésta es una de las diferencias esenciales que separan la risa festiva popular de la risa puramente satírica de la época moderna. El autor satírico que sólo emplea el humor negativo, se coloca fuera del objeto aludido y se le opone, lo cual destruye la integridad del aspecto cómico del mundo; por lo que la risa negativa se convierte en un fenómeno particular. Por el contrario, la risa popular ambivalente expresa una opinión sobre un mundo en plena evolución en el que están incluidos los que ríen” (Bajtín 1998, p. 17).
} 
Media y Renacimiento; se basa en un tipo de crítica "jocosa, burlesca y festiva" que buscaba únicamente producir la franca hilaridad del lector. ${ }^{2}$ $\mathrm{Su}$ objetivo era divertir y regenerar la vida a través de la risa. Este tipo de risa se encuentra en la obra de Rabelais, en la que se emplean toda una serie de elementos carnavalescos (la escatología, la caricatura, la lujuria, la gula, ${ }^{3}$ etcétera), cuyo propósito se centra en producir una risa "catárquica", de regeneración vital. Uno de los rasgos principales de este tipo de sátira es la importancia que se le da al exceso. Por este motivo, la sátira gramatical en el Gargantúa (1534), por ejemplo, aparece en forma de exceso de palabrería y de latinajos farragosos, retorcidos y macarrónicos que los maestros escolásticos de latinidad, como Thubal Holofernes, pretenden llenar en la cabeza del pobre gigante. ${ }^{4}$

Otra de las más importantes contribuciones de la risa carnavalesca a la sátira es la caracterización física del dómine. Los rasgos del profesor de latinidad suelen verse deformados para conseguir una imagen caricaturizada despreciable. Así, uno de los autores más destacados que emplea este recurso es Quevedo en el Licenciado Cabra de su Buscón (1626). Este personaje aparece descrito físicamente como una especie de fantoche grotesco que contribuye a la sordidez del lugar de estudio y de lo que allí se aprende. ${ }^{5}$ También Vicente Espinel emplea ciertos rasgos carnavalescos cuando describe a uno de los dómines que se muestran en su obra La vida del escudero Marcos Obregón (1618), puesto que aparece

${ }^{2}$ Cf. Lechte 1996, p. 25: "El aspecto más importante del carnaval es la risa. Pero la risa de carnaval no puede equipararse a las formas específicas que adopta en la conciencia moderna. No es meramente paródica, irónica o satírica. La risa de carnaval no tiene objeto. Es ambivalente. La ambivalencia es la clave de la estructura carnavalesca".

${ }^{3}$ Cf. Lechte 1996, p. 26: "La degradación, el envilecimiento, el cuerpo y todas sus funciones - especialmente la defecación, la orina y la cópula - forman parte integrante de la experiencia ambivalente del carnaval".

${ }^{4}$ La actividad educativa de Holofernes se ve en el capítulo 14, en la edición del Gargantúa de Alicia Yllera, pp. 133-136.

${ }^{5}$ La descripción del Licenciado Cabra de Quevedo (1996, pp. 115-117) comienza así: "Entramos el primer domingo después de Cuaresma en poder de la hambre viva, porque tal lacería no admite encarecimiento. Él era un clérigo cervatana, largo sólo en el talle, una cabeza pequeña, pelo bermejo (no hay más que decir para quien sabe el refrán), los ojos avecindados en el cogote, que parecía que miraba por cuévanos, tan hundidos y oscuros, que era buen sitio el suyo para tiendas de mercaderes; la nariz, entre Roma y Francia, porque se le había comido de unas búas de resfriado, que aun no fueron de vicio porque cuestan dinero; [...]." 
como una figura absurda y ridícula más por sus actos que por su físico, al ponerse a perseguir un gallo mientras grita latinajos absurdos. ${ }^{6}$

A partir del siglo XVIII, la caricaturización de la figura del dómine se modera y, aunque sigue manteniendo ciertos rasgos grotescos, éstos se subordinan más al "decoro" que predominaba en la estética de la época. Precisamente, los autores del siglo XVIII serán los que más van a emplear en la sátira gramatical un tipo de crítica irónica y mordaz, bastante alejada de la risa carnavalesca. Este modo de sátira pasa de la risa festiva a una crítica de comportamientos y de actitudes con un objetivo moralizante de conseguir una mejor formación tanto educativa como cultural. Se trata de una "denuncia" de maneras y de vicios que se desvían del recato, la moral y las buenas costumbres. La sátira de esta época es esencialmente burguesa y las formas de pensar que se defienden en ella se centran en la moralidad burguesa. También suele aparecer en su versión de diatriba, al centrarse en criticar de forma muy individualizada a un personaje determinado cuyos actos se desvían de la enseñanza racional.7 La "diosa razón" será la principal guía de esta sátira. Los irracionales comportamientos de los dómines, sus deformados físicos y sus absurdas enseñanzas se apartan profundamente de los principios razonables de lo que tendría que ser un educador y de la manera en la que tendría que ejercer su aprendizaje.

La sátira gramatical del siglo XVIII se plasma en el preceptor Don Juan de Dios de La Vida (1743, con ampliaciones posteriores), de Diego de Torres Villarroel; en los dómines Taranilla y Zancas-Largas del Fray Gerundio de Campazas (1758), del padre José Francisco de Isla, o en La Gramática del dómine Don Supino (1790), de Manuel de Vegas y Quintano. ${ }^{8}$ En todos ellos (aunque en Torres Villarroel bastante menos)

${ }^{6}$ Ese latinajo es el siguiente: Non te peto, piscem peto, cur me fugis, galle? (Espinel 2000 , p. 154), basado en el texto de Festo (Fest. p. 285 M): “non te peto, piscem peto. Quid me fugis, Galle” quia murmillonicum genus armaturae Gallicum est, ipsique murmillones ante Galli appellabatur.

${ }^{7}$ Un ejemplo de ello es la obra de Forner Los Gramáticos. Historia chinesca (1782), que es una invectiva personal para criticar los malos enseñantes de latinidad a través de la familia Iriarte, en especial contra Juan y Tomás de Iriarte.

${ }^{8}$ Un análisis exhaustivo de la figura del dómine en estas obras lo desarrollé en el libro que hice en colaboración con García Jurado (2011), donde hacemos un recorrido evolutivo de la presencia de la figura del maestro de latinidad desde el siglo XV hasta nuestros días. Un estudio más concreto y exclusivo del profesor de latinidad en Vives, Quevedo, Isla y Vegas y Quintano lo tenemos en Espino Martín 2002, pp. 2457-2468. 
se da la descripción de un maestro de latinidad cuyas enseñanzas sólo pueden acarrear que los niños salgan idiotas, ociosos e ignorantes. Si en la caracterización física suelen seguir, aunque más suavizado y menos caricaturesco, el modelo que reflejara Quevedo para su Licenciado Cabra, no obstante el principal objetivo de la sátira gramatical del XVIII es el método educativo de los dómines. Por este motivo, en la mayoría de estas sátiras se suele contraponer el método pernicioso del dómine al aprendizaje que tendría que ser el más adecuado según los principios del pensamiento ilustrado. La burguesía y baja nobleza buscaban una importante renovación y reforma de la enseñanza tradicional y eclesiástica. La educación del Antiguo Régimen era considerada decadente y poco adecuada a los nuevos tiempos, donde ya no se buscaba tanto la formación religiosa y espiritual, sino el progreso material y económico. Por ello, sus miras críticas se centran fundamentalmente en desacreditar a los "dómines" cuyo sistema de enseñanza inadecuado y obsoleto constituye los cimientos de un Estado ineficaz y estéril.

Seguidamente, analizaremos cómo se manifiesta la sátira gramatical en la obra de Lizardi, qué objetivos tiene según el tipo de picaresca que éste desarrolla y cómo aparece expuesta de acuerdo con las líneas directrices que la definen en relación con los autores que anteriormente a él la han empleado y han influido en la elaboración de su obra.

\section{El empleo del "género picaresco" en Lizardi según su contexto histórico-cultural}

Cuando José Joaquín Fernández de Lizardi escribe su Periquillo Sarniento en 1813, la sociedad virreinal de la Nueva España se encontraba en un profundo proceso de descomposición. Los deseos separatistas mexicanos empezaron a hacerse cada vez más relevantes durante el reinado de Carlos III y se agudizaron especialmente con la expulsión de los jesuitas a partir de 1767. Los principales difusores de un cambio político y de la secesión con España fue la clase media criolla. Tradicionalmente, los criollos fueron apartados de los órganos de poder por la aristocracia española liderada por el virrey y las instituciones eclesiásticas. Esto produjo un fuerte resentimiento que se vio acrecentado por una serie de condicionantes: los ecos de la independencia de los Estados Unidos, el triunfo de la burguesía en la Revolución francesa, la entrada en México de toda una serie de libros que propugnaban las ideas ilustradas de 
Montesquieu, Voltaire o Rousseau; las críticas extranjeras al proceso colonizador español; los viajes científicos de personajes como Humboldt que mostraban un interés europeo por la geografía, la flora y la fauna de Sudamérica; el liberalismo político generado por la burguesía europea y su "anti-aristocratismo", así como los graves problemas económicos y políticos. Todos ellos fueron, en mayor o menor medida, los detonantes para que la clase media criolla mexicana fuera desarrollando un sentimiento nacionalista cada vez más intenso.

El principal instrumento de crítica y sátira contra el régimen establecido fueron los panfletos y la prensa periodística. La guerra de la Independencia española contra Napoleón, así como la promulgación de la Constitución de Cádiz de 1812 produjo un debilitamiento ${ }^{9}$ de las instituciones coloniales del Antiguo Régimen y permitió una mayor proliferación de la prensa escrita, que ayudó a alimentar la causa independentista. Precisamente, fue José Joaquín Fernández de Lizardi uno de los principales articulistas satíricos y críticos que escribió durante este periodo en diversos periódicos de relevancia como fueron el Diario de México o El Pensador Mexicano. Lizardi pertenecía a la clase mediabaja criolla, en una vertiente que se puede calificar de "letrada" e "intelectual". El poderoso bagaje cultural que el autor mexicano disponía le daba consistentes y profundos argumentos como para atacar el sistema colonial y represivo del virreinato español. Muchas veces sus lecturas de los clásicos, así como de los principales autores ilustrados le sirvieron como apoyo decisivo para defender sus ideas sobre la independencia de México respecto a España.

En 1814 se produce un acontecimiento decisivo que cambiaría el rumbo satírico-periodístico de Lizardi. Se trata del regreso de Fernando VII a España. Inmediatamente, el rey español inicia toda una serie de acciones represivas contra los focos liberales tanto políticos como sociales. Estas medidas también se van a extender a las colonias, de forma que el virrey Félix Calleja (1753-1828) prohíbe la libertad de prensa y produce un endurecimiento del papel de la Inquisición que extenderá con mayor contundencia a la censura de todo papel escrito. Por estos motivos, Lizardi se ve con cada vez mayores dificultades para escribir

${ }^{9}$ Una consecuencia clara de este debilitamiento fue el levantamiento de Miguel Hidalgo en 1810 . 
sus panfletos ${ }^{10}$ y para publicar su nuevo periódico Alacena de frioleras. El autor de El Periquillo Sarniento se da cuenta de que para poder difundir sus "peligrosas" ideas separatistas y liberales tiene que emplear otro medio literario. Por ello, Lizardi decide escribir sus críticas a la sociedad colonial en clave picaresca. En 1815 publica El Prospecto de la vida e aventuras de Periquillo Sarniento, que era un primer anuncio de lo que iba a ser la primera novela hispanoamericana moderna El Periquillo Sarniento, la cual acabó de escribir entre 1816 y 1817. La idiosincrasia que motivó la escritura de esta obra motiva que su fondo picaresco no sea el mismo que el resto de las novelas que han empleado este género literario. En primer lugar, el objetivo del escritor no es tanto literario como político-filosófico. Cuando el autor del Lazarillo, por poner un ejemplo, escribe su obra, aparte de la crítica social que trasluce en ella, se nota cómo se van desarrollando literariamente unos personajes, una ambientación, una estructura, un estilo, etcétera, que hace que acabe convirtiéndose en una auténtica obra literaria, donde el elemento satírico está subordinado a su molde artístico. No obstante, en el caso de El Periquillo el proceso es prácticamente opuesto. La picaresca sirve al escritor para defender sus propias ideas políticas y sociales. Así pues, se narra la historia de un criollo, perteneciente a la clase media baja que, por culpa de la presión familiar, inicia un lamentable proceso educativo y formativo que lo llevará irremediablemente a una degradación continua de su situación profesional y de su moral. Al final de su vida se da cuenta de todos sus errores, así como de los "perniciosos" engranajes sociales que lo empujaron a su perdición vital. Por este motivo, logra redimirse y obtiene una profesión más o menos digna, y escribe la historia de su vida para que no les pase lo mismo a sus descendientes y se les prevengan de la sociedad que los rodea.

En medio de los sucesos que van acaeciendo al protagonista se incluyen unos farragosos y densos excursos morales que pretenden criticar sus propios actos, así como ofrecer la alternativa de lo que tendría que haber sido correcto, o bien se critican los organismos e instituciones sociales y se proponen soluciones a sus fallos y errores. El hecho de que Periquillo haya ejercido varias profesiones, permite a Lizardi reflejar un cuadro completo y complejo de la sociedad mexicana, para que toda ella se vea

${ }^{10}$ Los panfletos que escribió en este tiempo se recopilan bajo el título de Caxoncito de la alacena. 
comprometida en el deseo de cambio contra la clase española dominante que es la causante de todos los males que el propio escritor refleja a través de las desventuras del protagonista. De hecho, éste viaja a la isla de Utopía, donde descubre una sociedad correctamente organizada según los ideales rousseaunianos e ilustrados. Esto permite a Lizardi sintetizar en un capítulo lo que sería la sociedad ideal de burguesía ilustrada mexicana frente a la decadente sociedad colonialista del Antiguo Régimen español.

Por otra lado, en Don Catrín de la Fachenda (publicado póstumamente en 1832) que se podría considerar la segunda parte de El Periquillo, su protagonista es un criollo ocioso y malcriado que no reconoce los errores de sus actos y que lleva su "hidalguía" perezosa e indolente hasta el final. En esta obra Lizardi arremete contra los llamados "catrines", que aunque, ya de natural han nacido así, son reforzados por una clase criolla de orígenes aristocráticos, indolente y permisiva que a su vez está inmersa en una educación hipócrita y engañosa. Los "catrines", por un lado, no desean trabajar porque han sido criados en la holgazanería tanto familiar como educativa (por ejemplo: la negativa de Don Catrín a desempeñar actividades que requieren mucho esfuerzo y que denotan "gañanería", como cigarrero, escribiente, portero, labrador...); por otro lado, a los "empleos" que por su considerable esfuerzo son rechazados por los "catrines", se añaden los que son complicados para acceder a causa del bloqueo de ciertos grupos profesionales o del propio gobierno (por ejemplo: el comercio exterior controlado por los "españoles de la otra orilla" o "prácticas artesanales" tuteladas por gremios al estilo medieval, dirigidos por el "proteccionismo gubernamental"). ${ }^{11}$ De este modo, los "catrines" se dedican a vivir en la trampa y en el engaño, y a falsear una realidad que es constantemente relativizada a su voluntad. Los catrines son perniciosos e impiden el progreso del país.

Si el objetivo de El Periquillo era denunciar las trabas educativas y sociales que, por incompetencia e ineficacia, deben desaparecer, ya que impiden la mejora de los propios "periquillos", en el Don Catrín, en cambio, se propugna la desaparición de los propios "catrines", "como una necesidad, dado que es la única solución para evitar el mal ejemplo y promover el sentido productivo de la sociedad, presente en el resto de las clases". ${ }^{12}$ A diferencia de los "periquillos" que desean trabajar y

${ }^{11}$ Cf. Oviedo \& Mejías 2001, p. 33.

${ }^{12}$ Cf. Oviedo \& Mejías 2001, p. 29. 
progresar en el sistema social y se percatan de los errores que pretenden enmendar, los catrines se aprovechan del sistema y se regodean en él. La única manera de que la sociedad mexicana progrese es fomentando la buena educación y el progreso laboral y social de los "periquillos", y a la vez obligar a los "catrines" a que se transformen en "periquillos" y no dejarles opción a que se deleiten y reproduzcan la ineficacia social que genera el no hacer nada. Tal y como era el tipo de educación y el estado social de la época de Lizardi sucedía el fenómeno contrario a lo que el escritor mexicano considera que es el progreso: los "catrines" son recompensados y los "periquillos" son reprimidos y prácticamente, obligados a convertirse en "catrines". Por eso, Lizardi defiende la necesidad tanto física como moral de un trabajo digno para el ser humano, y arremete contra las clases improductivas, ya sea de adinerados ociosos o de mendigos y prostitutas menesterosas, que se sitúan en los extremos de las capas sociales: "todos ellos mancomunados por ese rasgo común que es el desprecio al trabajo". ${ }^{13}$ Por otra parte, también censura los monopolios corporativistas que impiden a los "periquillos" subir en la escala social. Su ideal es ilustrado y liberal, basado en tres principios básicos: calidad educativa, libertad laboral y estímulo al trabajo bien realizado y productivo. Apuesta por una clase media de pequeñosburgueses debidamente educados e ilustrados que impulsen la mejora y crecimiento del país.

En definitiva, el autor de El Periquillo se muestra como un burgués liberal que se enfrenta contra un poder establecido que impide a la burguesía desarrollarse como clase política y poder implantar sus ideales que consideran que son los necesarios para que la sociedad en conjunto viva mejor. A estos ideales, que se comparten con toda la burguesía europea, se añade el factor extranjerizante que supone ser dominado por una aristocracia que no es autóctona, sino conquistadora y que proviene de un lugar alejado. Este hecho da a la causa burguesa un mayor resentimiento y virulencia en contra del poder establecido que considera perniciosa para el desarrollo social, lo cual no dejaba de ser cierto ya que éste se reflejaba en una profunda crisis económica y financiera. En todo este panorama, El Periquillo y Don Catrín son obras que según el modelo literario picaresco y la mentalidad ilustrada de "enseñar deleitando" supone una crítica de toda la tensión de una sociedad en descomposición.

${ }^{13}$ Cf. Oviedo \& Mejías 2001, pp. 32-33. 
Por ello, Lizardi propone una novela donde la picaresca está al servicio de la defensa del ideal social y político-burgués, y en la que todos los elementos picarescos y satíricos son instrumentalizados al máximo para que difundan la chispa de la insurrección y el descontento de las capas bajas y medias de la sociedad mexicana contra la élite "invasora".

\section{La "sátira gramatical" en la obra picaresca de Lizardi}

Si Periquillo y Don Catrín están condicionados por un objetivo políticosocial utópico que busca desplazar a la aristocracia española dominante e instaurar una sociedad liberal según las ideas ilustradas y según el modelo burgués, la educación desempeña un papel sustancial para ello. El autor mexicano considera que las instituciones educativas, así como sus métodos pedagógicos y sus enseñanzas constituyen el centro de la decadencia social y el motivo de la degradación de los individuos, representados por los protagonistas de sus novelas.

La madre de Periquillo defiende la importancia de los estudios superiores para mantener el prestigio de su linaje familiar ${ }^{14}$ frente al padre que prefiere que el hijo estudie un oficio, ya que, si sigue una carrera universitaria, acabará volviéndose un holgazán, jugador, vicioso y pervertido, ${ }^{15}$ tal como sucedía con muchos nobles procedentes de familias de abolengo. Finalmente, triunfa el punto de vista de la madre y Periquillo inevitablemente cae en las consecuencias perjudiciales de los estudios superiores que desaconsejaba el padre, lo que le lleva a la vida de penurias que proféticamente había anticipado su progenitor. Lizardi demuestra así que la educación es fundamental para que los individuos salgan viciosos o bondadosos, productivos o improductivos, en definitiva, buenos o malos ciudadanos, ya que, como afirma el padre de Peri-

14 Fernández de Lizardi 1962, p. 27: "No, señor — replicaba mi madre toda electrizada -, si usted quiere dar a Pedro algún oficio mecánico, atropellando con su nacimiento, yo no, pues aunque pobre, me acuerdo que por mis venas y por las de mi hijo corre la ilustre sangre de los Ponces, Tagles, Pintos, Velascos, Zumalacárreguis y Bundiburis”.

${ }^{15}$ De hecho, seguidamente a la afrimación de la madre del Periquillo, Lizardi presenta el ejemplo de uno de ellos que iba a ser ajusticiado a muerte por haber matado a un maromero y que finalmente por influencia del Virrey se le conmutó la pena por el encarcelamiento. Este joven noble se anticipa al personaje de Don Catrín que es precisamente otro ejemplo claro de este tipo de jóvenes de ascendencia noble que, por una educación desviada, se ven envueltos en un tipo de vida ociosa y viciosa, y que, además, son inconscientes de sus propios defectos y de los errores de su vida, de forma que no se arrepienten de nada. 
quillo, "lo que envilece son las malas acciones, mala conducta y la mala educación". ${ }^{16}$ Conforme se desarrolla la novela, se apreciará que esa "buena o mala educación" depende en parte de ciertos profesores que la imparten y, también, de un sistema educativo pernicioso.

\section{La figura satírico-carnavalesca del dómine}

El panorama general del sistema educativo tiene su plasmación concreta en las figuras del profesor de primeras letras y de latinidad. Antes de acceder a la educación secundaria, Periquillo nos describe a tres profesores: el primero se muestra bastante indulgente, indolente e incompetente; el segundo, muy severo, adusto y riguroso, y el tercero se presentaba como un profesor de ideas modernas, defensor de la naturaleza y seguidor de los principios ilustrados. De estos tres enseñantes, el segundo es el que nos interesa, pues si bien era un maestro de primeras letras, donde no se incluía el aprendizaje de la latinidad, no obstante, Lizardi se basó en los profesores de latinidad de Torres Villarroel y del padre Isla para recrear el físico, la personalidad y los "modos" educativos de este personaje.

En primer lugar, veamos en una descripción inicial de su físico y su personalidad la gran semejanza con el dómine Zancas-Largas de Isla. El jesuita nos muestra una visión caricaturizada, heredera de la fisonomía del quevedesco licenciado Cabra y que responde a la "risa carnavalesca" de la que habla Bajtín:

Era éste un hombre alto, derecho, seco cejijunto y populoso; de ojos hundidos, nariz adunca y prolongada, barba negra, voz sonora, grave, pausada y ponderativa furioso tabaquista, y perpetuamente aforrado en un tabardo talar de paño pardo, con uno entre becoquín y casquete de cuero rayado, que en su primitiva fundación, había sido negro, pero ya era del mismo color que el tabardo. ${ }^{17}$

Por otra parte, el maestro de Periquillo se caracterizaba porque

era alto, seco, entrecano, bastante bilioso e hipocondriaco, hombre de bien a toda prueba, arrogante lector, famoso pendolista, aritmético diestro y muy regular estudiante; pero todas estas prendas las deslucía su genio tétrico y duro. ${ }^{18}$

\footnotetext{
${ }^{16}$ Fernández de Lizardi 1962, p. 29.

17 Isla 1995, p. 283.

${ }^{18}$ Fernández de Lizardi 1962, p. 22.
} 
A la semejanza sintáctica en la descripción se añade el mismo uso de los adjetivos "alto" y "seco". Por otra parte, "la barba negra" de Isla se asemeja al "entrecano" de Lizardi, así como se puede apreciar que, aunque semánticamente no tienen nada que ver, existe una gran identificación fonética entre "furioso tabaquista" y "famoso pendolista" ${ }^{19}$ Después de esta breve descripción física, Lizardi se centra en el modo de enseñar a través del castigo físico y de la violencia. Un aspecto que inquietaba mucho en el siglo XVIII, ya que era considerado como una de las lacras de la enseñanza tradicional que provocaba una formación desviada del niño. En este punto, Lizardi tendrá como modelo a Don Juan de Dios, preceptor que aparece como personaje en la Vida de Diego de Torres Villarroel. Si bien comparte rasgos en su físico y su actitud con el maestro de Periquillo y con el propio Zancas-Largas, no obstante su mayor punto de coincidencia está en la complacencia del uso del castigo físico y la violencia como único método para que los alumnos aprendan. Torres Villarroel describe el uso de la violencia en los siguientes términos:

Murió pocos años ha el maestro de mis primeras letras, y lo temí hasta la muerte; hoy vive el que me instruyó en la gramática, y aún lo temo más que a las brujas, hechizos, las apariciones de los difuntos, los ladrones y los pedigüeños, porque imagino que aún me puede azotar; estremecido estoy en su presencia, y a su vista no me atreveré a subir la voz a más tono que el regular y moderado. Ello parece disparate, proferir que se hayan de criar los viejos con azotes, como los niños; pero es disparate apoyado en la inconstancia, soberbia, rebeldía y amor propio nuestro, que no nos deja hasta la muerte. Ahora me estoy acordando de muchos sujetos que, si los hubieran azotado bien de mozos y los azotaran de viejos, no serían tan voluntariosos y malvados como son [...]. El palo y el azote tiene más buena gente que los consejos y los agasajos. Finalmente, en todas edades somos locos, y el loco por la pena es cuerdo. ${ }^{20}$

Podemos comprobar que el talante bastante conservador de Torres Villarroel le lleva a considerar la violencia como necesaria y beneficiosa para no formar a hombres ni "voluntariosos", ni "malvados". Al con-

${ }^{19} \mathrm{Si}$ bien, en líneas generales, Lizardi se deja llevar por el modelo del dómine de Isla, evita la descripción de su forma de vestir, así como su forma de hablar que el jesuita lo centra en sus latinajos.

20 Torres Villarroel 1995, p. 96. 
trario de esta opinión, Lizardi sigue un punto de vista de respeto hacia la infancia y los derechos mínimos del niño, tal y como preconizaba la pedagogía ilustrada y rousseauniana. Por este motivo, describe los actos violentos del dómine con tono de censura y repudio. Al final, debido a su desprecio de la "violencia educativa", le lleva a hiperbolizarla en su relato, por lo que ésta se hace tan feroz que Periquillo ruega a sus padres que le sacaran de las garras del "temible" maestro:

Tal era mi nuevo preceptor, de cuya boca se había desterrado la risa para siempre, y en cuyo cetrino semblante se leía toda la gravedad de un Areópagita. Era de aquellos que llevan como infalible el cruel y vulgar axioma de que la letra con sangre entra, y bajo este sistema era muy raro el día que no nos atormentaba. La disciplina, la palmeta, las orejas de burro y todos los instrumentos punitorios estaban en continuo movimiento sobre nosotros; y yo, que iba lleno de vicios, sufría más que ninguno de mis condiscípulos los rigores del castigo [...].

Así me sucedía, que cuando iba o me llevaban a la escuela, ya entraba ocupado de un temor imponderable; con esto mi mano trémula y mi lengua balbuciente ni podían formar un renglón bueno ni articular una palabra en su lugar. Todo lo erraba, no por falta de aplicación, sino por sobra de miedo. A mis yerros seguían los azotes, a los azotes más miedo, y a más miedo más torpeza en mi mano y en mi lengua, la que me granjeaba más castigo. ${ }^{21}$

La influencia de Torres Villarroel se puede apreciar no tanto de forma positiva, sino negativa en cuanto a que Lizardi entra en un diálogo con el autor de la Vida para contrastar su punto de vista que resulta bastante opuesto a su fuente literaria.

Después de su segundo maestro, Periquillo acaba en manos de un profesor que se caracterizaba por ser joven, elegante, limpio, con una cara que "manifestaba la dulzura de su corazón", con una "prudente" sonrisa y con unos ojos que "inspiraban confianza y respeto". Su método de enseñanza, totalmente contrario al anterior preceptor, se basaba en el análisis y contemplación de la naturaleza: “¿ves, hijo, qué primores encierra la Naturaleza, aun en cuatro hierbecitas y unos animalitos que aquí tenemos? Pues esta Naturaleza es la ministra de Dios que creemos y adoramos". ${ }^{22}$ Junto a la admiración por el aprendizaje basado en la

${ }^{21}$ Fernández de Lizardi 1962, p. 22.

${ }^{22}$ Fernández de Lizardi 1962, p. 24. 
naturaleza, el tercer maestro de Periquillo se caracteriza por su moralidad y por enseñar los principios inherentes del ser humano, basado en un método de aprendizaje en el que la enseñanza se debía hacer a través del "amor" y de la "dulzura" hacia el niño, de forma que "debe amar, respetar y obedecer lo mismo que a su "padre". Por ello mismo, le debía considerar como "padre" y "amigo". Como consecuencia de este modo de educar, el nuevo maestro despreciaba inevitablemente el castigo físico, porque consideraba que

El azote [...] se inventó para castigar afrentando al racional, y para avivar la pereza del bruto que carece de razón; pero no para el niño decente y de vergüenza que sabe lo que le importa hacer y lo que nunca debe ejecutar, no amedrentado por el rigor del castigo, sino obligado por la persuasión de la doctrina y el convencimiento de su propio interés. ${ }^{23}$

Con todo ello, este maestro seguía la pedagogía ilustrada, de autores como Rousseau, Fleuri o Pinton. Precisamente de estos dos últimos el maestro recomendaba a Periquillo que leyera sus obras como Los niños célebres, Las recreaciones del hombre sensible "y otras obritas semejantes". Periquillo guardó hacia su último maestro de primeras letras un profundo cariño, veneración y obediencia. La semblanza del tercer maestro sirve precisamente a Lizardi para oponer la mala enseñanza del segundo profesor que era la que se solía dar en la sociedad mexicana, frente a la buena instrucción que tendría que darse en el nuevo siglo guiada por el pensamiento y la pedagogía ilustrada que salvaguardaba los derechos morales y humanos básicos para una formación provechosa y alejada del vicio.

Aparte de mostrar un objetivo ideológico en el contraste entre el segundo y tercer maestro de Periquillo, se puede observar que Lizardi traslada a los enseñantes de primeras letras ascendientes literarios de los dómines de latinidad que él había podido leer en las obras que ha tenido como referencia para la creación de su Periquillo. Precisamente, este contraste entre un maestro "bueno" y uno "malo" lo podemos ver en la oposición que muestra Vicente Espinel en su Vida entre un dómine anónimo y Don Juan Cansino (oposición que tiene a su vez su ascendiente en los Diálogos de Vives entre un magister diligentissimus y probissi-

\footnotetext{
${ }^{23}$ Fernández de Lizardi 1962, p. 25.
} 
mus y el magister al que los niños califican por su mal carácter de "Philopono tétrico"). ${ }^{24}$ Espinel muestra la oposición entre un profesor cuyos rasgos más identificables son su jactancia, brutalidad y un bochornoso modo de enseñar el latín, frente a Don Juan Cansino caracterizado por su silencio, modestia, moralidad y empleo de un método humanista de instruir a los alumnos en los autores clásicos más puros. De hecho, antes de introducir la figura de Juan Cansino, Espinel afirma que el buen profesor "ha de ser el maestro lleno de mansedumbre con gravedad, para que juntamente le amen y estimen, y haga el mismo efecto en el discípulo, no perdiéndole un punto de su vista si no fuere los ratos disputados para el gusto de sus padres o cuando el niño le tuviere con sus iguales; [...]". ${ }^{25}$ Según esto último, además del contraste de dos maestros caracterizados por una perniciosa pedagogía existen otros puntos coincidentes entre el ideal pedagógico de Espinel y el de Lizardi, como el respeto, cariño, y amor prácticamente paternal que han de tener los niños hacia los profesores que éstos se han ganado, previamente, con paciencia, modestia y humildad. Para ello, el maestro ha de comportarse acorde a la mentalidad rousseauniana que pone en práctica un tipo de educación naturalista y "paido-céntrica" basada en que el profesor logre sacar del niño todas sus cualidades innatas a través de un trato cariñoso y familiar y de estar en contacto con el medio natural que le rodea. No se trata tanto de que el alumno sea un mero receptáculo de reglas y ejemplos, sino de que participe activamente en la educación a través de la figura del maestro que le ayudará a potenciar todas sus cualidades naturales.

En definitiva, para la caracterización de los maestros iniciales de Periquillo, Lizardi se ha fundamentado en la semblanza de los maestros de latinidad de tres autores picarescos españoles como fueron Espinel, Torres Villarroel e Isla (e indirectamente Quevedo). No obstante, cuando Periquillo pasa a la enseñanza secundaria, una vez que su madre haga valer su voluntad y desoiga los consejos del padre, Lizardi se empieza a centrar ya no tanto en el carácter de los enseñantes, que consideraba trascendentales en la primera formación del niño, sino en el método de enseñanza. Será ahí precisamente cuando nos encontramos con el primer acercamiento al aprendizaje institucional.

${ }^{24}$ Además ambos se diferencian por métodos distintos que se corresponden a su físico y carácter (cf. Vives 1987, pp. 40-47).

${ }^{25}$ Espinel 2000, pp. 181-182. 


\section{La enseñanza de la latinidad}

El primer peldaño de ese "aprendizaje institucional" será precisamente la instrucción de la lengua latina, basada en el memorismo de gran cantidad de reglas, preceptos y ejemplos, y en la ausencia de los autores clásicos más puros:

Finalmente llegó el día en que me pusieron al estudio, y éste fue el de don Manuel Enríquez, sujeto bien conocido en México, así por su buena conducta, como por su genial disposición y asentada habilidad para la enseñanza de la gramática latina, pues en su tiempo nadie le disputó la primacía entre cuantos preceptores particulares había en esta ciudad; mas por una tenaz y general preocupación que hasta ahora domina, nos enseñaba mucha gramática y poca latinidad. Ordinariamente se contentan los maestros con enseñar a sus discípulos una multitud de reglas que llaman palitos, con que hagan unas cuantas oracioncillas, y con que traduzcan el Breviario, el Concilio de Trento, el catecismo de San Pío V, y por fortuna algunos pedacillos de la Eneida y Cicerón. ${ }^{26}$ Con semejante método salen los muchachos habladores y no latinos, como dice el padre Calasanz en su Discernimiento de ingenios. ${ }^{27}$ Tal salí yo, y no podía salir mejor. Saqué la cabeza llena de reglitas, adivinanzas, frases y equivoquillos latinos; pero en esto de inteligencia en la pureza y propiedad del idioma, ni palabra. Traducía, y no muy mal y con alguna facilidad las homilías del Breviario, y los párrafos del catecismo de los curas; pero Virgilio, Horacio, Juvenal, Persio, Lucano, Tácito y otros semejantes hubieran salido vírgenes de mi inteligencia si hubiera tenido la fortuna de conocerlos, a excepción del primer poeta que he nombrado, pues de éste sabía alguna cosita que le había oído traducir a mi sabio maestro. También supe medir mis versos, y lo que era hexámetro, pentámetros, etcétera; pero jamás supe hacer un dístico.

A pesar de esto, y al cabo de tres años, acabé mis primeros estudios a satisfacción, pues me aseguraban que era yo un buen gramático, y yo lo creía más que si lo viese. ¡Válgate Dios, por amor propio, y cómo nos engañan

${ }^{26}$ La Eneida de Virgilio y las cartas y discursos de Cicerón se habían establecido como los textos y autores canónicos para aprender latín. Eran los autores y obras que más se utilizaban en las escuelas jesuíticas que dominaban el panorama educativo del momento.

${ }^{27}$ Los escolapios seguían el método filológico y port-royalista opuesto al jesuítico. Cuando la Compañía fue expulsada en 1767, los seguidores de San José de Calasanz tomaron, en buena medida, las riendas de la enseñanza y siguieron los presupuestos educativos del racionalismo ilustrado, de modo que se volvieron difusores indirectos del despotismo ilustrado (cf. Espino Martín 2003, pp. 423-435). 
a ojos vistas! Ello es que yo hice mi oposición a toda gramática, y quedé sobre las espumas, mi maestro y convidados muy contentos, y mis amados padres más huecos que si me hubiera opuesto a la magistral de México, y la hubiera obtenido. ${ }^{28}$

De alguna manera, el profesor de latinidad que ya tiene nombre y apellidos representa el puente entre la primeras letras (se sigue individualizando el aprendizaje en una persona) y la enseñanza superior. Por este motivo, ahora Lizardi se centra más en el método educativo y académico de Don Manuel Enríquez, ${ }^{29}$ y no tanto en su modo de ser y en su carácter como en los maestros anteriores. Si el segundo maestro de Periquillo deformaba la conducta del niño con su naturaleza agresiva, Don Manuel Enríquez le "viciará" en la aplicación del aprendizaje de una materia tan esencial para la formación posterior, como era la lengua latina. Esta desviación pedagógica se irá acrecentando según vaya ascendiendo el protagonista en el sistema educativo. Por este motivo, más adelante, el peor latín es el que precisamente aprenda ya en la universidad.

El modo de enseñar la latinidad del "dómine" de Periquillo ya partía de lo que se ha llamado un método barroquizante e hispanizante del aprendizaje gramatical. ${ }^{30}$ Durante el siglo XVII los jesuitas toman el control de prácticamente toda la enseñanza "pre-universitaria" que tenía como centro la enseñanza de la lengua latina. En afán de que los alumnos crearan composiciones retóricas que alabaran piadosamente las virtudes de la Iglesia, les lleva progresivamente a "barroquizar" la enseñanza del latín al fundar su aprendizaje en la memorización de gran cantidad de reglas gramaticales, de excepciones y de ejemplos; ejemplos que, por otro lado, no se solían basar en autores clásicos, sino en frases creadas artificialmente por los propios preceptores, por lo que adolecían de contaminación de la lengua española (la llamada "hispanización”). Por otra

\footnotetext{
${ }^{28}$ Fernández de Lizardi 1962, pp. 33-34.

${ }^{29}$ Este nombre pudo ser inspirado por el gramático jesuita del Colegio Imperial de Madrid, Baltasar Enríquez, autor de una gramática latina de enfoque sustancialmente barroquizante e hispanizante y que llevaba el título de Advertencias de modos y tiempos (1683) (cf. Espino Martín 2007, pp. 365-367). Bien pudo ser usada por el propio Lizardi en sus años de aprendizaje de la lengua latina o bien pudo ser el preceptor particular que tuvo el propio Lizardi para mejorar sus estudios de latinidad.

${ }^{30}$ Nuestro estudio de tesis doctoral gira en torno a este método y a las gramáticas que lo empleaban: Espino Martín 2007. Una visión más panorámica la mostramos en nuestra comunicación: cf. Espino Martín 2008a, pp. 807-819.
} 
parte, esta hispanización se acrecentaba por el hecho de que en muchas gramáticas jesuíticas se incluían estructuras españolas que eran interpretadas desde el latín, sin que nunca hubieran llegado a existir en la lengua de Virgilio, con lo que se convierten en una mala interpretación latina de combinaciones lingüísticas de la lengua española (era la llamada figura de la suppletio). ${ }^{31}$ A la enseñanza barroquizante e hispanizante jesuítica, que ya de por sí mal-formaba el aprendizaje del buen latín, tenemos que añadir la mayor degradación a la que le sometían los llamados dómines. Éstos solían ser alumnos rebotados de las escuelas religiosas que, por su incapacidad, no habían pasado a estudios superiores, y que tenían como bagaje cultural su ignorancia en la latinidad. ${ }^{32} \mathrm{El}$ método barroquizante e hispanizante jesuítico ${ }^{33}$ servía de perfecto transmisor de la ignorancia del latín macarrónico que exhibían estos dómines a sus alumnos. Por este motivo, tantos autores literarios criticaron el pervertido modo de enseñar de los dómines particulares. Seguidamente, vemos en el propio Periquillo cómo su dómine le enseñaba lo que él mismo llama con ironía los "equivoquillos impertinentes" latinos que aprendió en su escuela de gramática y que son una muestra deformada del método hispanizante de la gramática jesuítica:

${ }^{31}$ La suppletio es una figura gramatical que se da en las gramáticas latinas desde la Edad Media. Nosotros hemos dedicado, aparte de continuas alusiones, un apartado exclusivo de nuestra tesis doctoral, para analizar este fenómeno en los manuales gramaticales jesuíticos desde el siglo XVI al XVIII: Espino Martín 2007, pp. 201-208. Por otro lado, Vicente Calvo ha estudiado este fenómeno gramatical en los manuales gramaticales medievales, denominados Grammaticae Proverbiandi, a los que dedicó su tesis doctoral: cf. Calvo, 1995.

32 Acerca de la condición laboral y educativa de estos dómines es muy interesante el artículo de Gil 1980, pp. 20-30.

33 Precisamente, la propia Compañía se da cuenta de cómo los excesos barrocos estaban perjudicando peligrosamente el nivel educativo y formativo de sus integrantes. Esta situación lleva a que el propio padre General Visconti en 1752 mande una carta (el título era De studiis humaniorum litterarum promovendis) a todos los Provinciales españoles, para que velen por la mejora de la enseñanza de las Humanidades en los colegios de la Compañía. Esta carta va a ser el impulso del movimiento reformista y renovador que se va a dar en varios enclaves como Villagarcía de Campos, conducido por el Padre Francisco Javier de Idiáquez; la universidad de Cervera, encabezado por el padre Bartolomé Pou, y en figuras concretas como el padre Andrés Marcos Burriel y el propio padre Francisco José Isla, que será el que, a través de la literatura, más va a arremeter contra la mala formación educativa y aquellos alumnos rebotados que acaban siendo "vergonzosos" dómines o predicadores. Para más datos cf. Espino Martín 2012. 
Así como en el estudio de la gramática aprendí varios equivoquillos impertinentes, según os dije, como Caracoles comes; pastorcito come adobes; non est peccatum mortale occidere patrem suum, y otras simplezas ${ }^{[34]}$ de éstas, así también en el estudio de las súmulas aprendí luego mil sofismas ridículos, de los que hacía mucho alarde con los condiscípulos más cándidos, como, por ejemplo: besar la tierra es acto de humildad: la mujer es tierra, luego, etc. $[\ldots]^{35}$

El pasaje anterior, bien pudiera estar inspirado en el siguiente de la Gramática del Dómine Don Supino, de Vegas y Quintano, en el que uno de los modos de enseñar del dómine, cuando se quería "desenfadar" y "serenar algo su cara de vinagre, y no molestar [...] tanto con el Ovidio y Virgilio", era:

Echando oraciones equívocas, cuyas personas estaban como agazapadas en las que tropezábamos como sapos, pues como eran: Yo que coso la bragas de mi marido; Tú has de parir en este mes: decíamos: Ego qui suo brachas mariti mei: Tu pariturus es isto mense, siendo así que las dos eran mujeres y muy mujeres, y nosotros con dos dedos de barbas. ¡O! Y lo que titubeábamos, quando nos decía: Yo cómo como tú: Aunque rio, no rio: con la condición de que no se había de echar verbo, que en esto estaba nuestra cavilación, y dándonos por vencidos, decía: Ego ut, ut tu: Etsi flumen, non flumen. Pero mas gustoso, quando nos ponía una oración, al parecer en romance, y era un latin hermoso, como Cara coles comes, que se entiende asi: id est tu tú, comes ó compañeros, coles reverenciarás cara las cosas amadas. ${ }^{36}$

La obra de este catedrático alcalaíno es considerada piedra angular en el subgénero literario de la "sátira gramatical" y sin duda fue una de las obras que más pudo influir en El Periquillo y en Don Catrín. ${ }^{37}$ En la

${ }^{34}$ Cuando Periquillo reconoce que la parte de latín que aprendió eran "simplezas" se mueve entre la novela picaresca y una Bildungsroman o novela de formación ético-moral, y va siendo consciente de los errores educativos que acabarán por ir configurando personalidades viciadas, mismas que integrarán una sociedad corrompida.

35 Fernández de Lizardi 1962, p. 36.

36 Vegas y Quintano 1790, p. 127.

37 Vegas y Quintano, en su obra Don Supino, no sólo desarrolló un exhaustivo e irónico análisis del sistema educativo y de la enseñanza de la lengua y literatura latina, sino que también redactó sus propios métodos de aprendizaje (Colección de las oraciones tomadas de las Epístolas de Cicerón [1789] y Arreglado método de la traducción latina [1800]), basados en una forma inductiva de enseñar el latín, la cual parte del texto 
obra del español se presenta la semblanza de un dómine que defiende, a través de un latín y unos autores bárbaros y macarrónicos, una enseñanza barroquizante e hispanizante que entra en controversia con un "crítico preguntador" que se podría considerar un alter-ego del propio autor y que ataca la enseñanza rocambolesca de Don Supino. En contraste, presenta un tipo de educación sensata, racional, basada en los principios port-royalistas e ilustrados.$^{38}$ La preocupación del "crítico preguntador" de Vegas y Quintano es la que se encuentra en el propio Periquillo que ha recibido esa educación y que gracias a la reflexión se vuelve "crítico" al cuestionar la validez de unos presupuestos educativos obsoletos y absurdos.

Si Periquillo razona sus faltas y se arrepiente de ellas, Don Catrín se queda únicamente con la óptica del mal aprendizaje y de su alabanza, con lo que consigue con mayor efectividad el objetivo irónico y literario de denuncia de lo que está criticando. A continuación, para que quede a la vista la diferencia del tono satírico respecto al Periquillo, se presenta el único pasaje en el que Don Catrín nos detalla su aprendizaje de la lengua latina:

Los maestros impertinentes me reñían y me obligaban a estudiar algunos ratos, y en éstos [...] ¡lo que es un talento agigantado!, en estos cortos ratos que estudié a fuerza, aprendí la gramática de Lebrija y toda la latinidad de Cicerón en dos por tres; pero con tal felicidad, que era la alegría de mis condiscípulos y la emulación de mis cansados preceptores. Aquéllos reían siempre que yo construía un verso de Virgilio o de Horacio, y éstos se rebanaban las tripas de envidia al oírme hacer régimen de una oración, porque yo les hacía ver a cada paso lo limitado de sus talentos y lo excesivo del mío.

Me decían, por ejemplo, que ego, mei no tenía vocativo, y yo les decía que era fácil ponérselo y necesario el que lo tuviera, pues no teniendo vocativo, no se podrá poner en latín esta oración: ¡Oh, yo, el más infeliz de los nacidos!, y poniéndole el vocativo ego, diremos: $O$ ego infelicior natorum!, y ya está vencida esta dificultad, y se podrán vencer así iguales injusticias y mezquindades de los gramáticos antiguos.

y se va complementando con la reglas gramaticales. Cf. Espino Martín 2010b, en vías de publicación.

38 El método educativo port-royalista (Espino Martín, 2010a, pp. 261-284) que se enseñó a lo largo del siglo XVII en las escuelas jansenistas de Port-Royal fue el paso para la enseñanza burguesa e ilustrada del XVIII. Sus principales ideólogos y maestros fueron Pascal, Lancelot, Arnauld y Nicole. Abogaban por una instrucción dulce, sin castigos severos, reflexiva, basada en el racionalismo cartesiano y del Brocense, y filológica, centrada especialmente en los autores clásicos de más pura latinidad (Cicerón, Virgilio, César, etc.). 
La oposición que hice a toda gramática fue de lo más lucido; ni uno hubo que no se tendiera de risa al oírme construir aquel trilladísimo verso de Virgilio:

Tityre tu patulae recubans sub tegmine fagi, que volví al castellano de este modo: Tu recubans, tú amarrarás; Tytire, a los títeres; patulae, de las patas; fagi, con una faja; sub tegmine, bajo de ciertos términos. Todos se reían, celebrando, ya se ve, mi habilidad; pero los maestros se ponían colorados, y aun me querían comer con los ojos desde sus sillas; ;tanta era la envidia que los agitaba! Pero en fin, yo recogí mis galas, mis padres quedaron muy contentos, y me pusieron a estudiar filosofía.

En esta facultad salí tan aprovechado como en gramática. A los dos meses ya argüía yo en bárbara que era un pasmo, y tenía un ergo tan retumbante que hacía estremecer las robustas columnas del colegio, siempre con asombro de mis condiscípulos y bastante envidia de mis maestros. Una ocasión, arguyendo con un rancio peripatético que defendía la existencia de cierto animal llamado entre sus antiguos patronos ente de razón, después de varias cosas que le dije, añadí este silogismo concluyente: Si per alicujus actus eficeretur entis ratio, maxime per huic: per huic non; ergo per nullius.

Las mesas y bancas de la clase resonaron con el palmoteo de los colegiales, que ya con su desentonada risa no dejaron proseguir el argumento; el sustentante me dio un apretado abrazo, y medio real de carita, diciéndome: - Tenga usted el gusto de que es más fácil concebir un ente de razón, que poner otro silogismo en un latín tan crespo y elegante. Todos me aplaudieron, todos me celebraron ese día, y no faltó quien escribiera el silogismo con letras de oro y lo pusiera sobre las puertas del aula con este mote: Ad perpetuam rei memoriam, et ad nostri Catrinis gloriam que resuelto a romance quería decir: Para gloria de la memoria de la historia latinoria del ilustrísimo, Catrín que es de los nuestros catrines. ¿Qué os parece, amigos y compañeros? ¿No os admira mi habilidad en tan pocos años? ¿No os espanta mi fama tan temprana? ¿No os ejemplariza mi conducta? Pues imitadme y lograréis los aplausos.

Así pasaron los dos años y medio del curso de artes, en los que tuve el alto honor de haber cursado la Universidad y el colegio con enteras aprobaciones de mis catedráticos y colegas. ${ }^{39}$

Junto con la obra de Vegas y Quintano, Lizardi también tuvo como principal referente el Fray Gerundio de Campazas, alias Zotes, del padre jesuita Isla. De hecho, el personaje de Don Catrín es muy similar a Gerundio, ya que aparte de parecerse en la forma de aprender latín ambos son unos perezosos e ineptos niños malcriados llenos de ocu-

\footnotetext{
${ }^{39}$ Fernández de Lizardi 2001, pp. 66-68.
} 
rrencias e insensateces que reciben el aplauso de la masa ignorante y la reprobación de un escaso número de personas instruidas y sensatas. El pasaje anterior sobre las ocurrencias disparatadas y sofísticas de Don Catrín muestra una especial similitud con el siguiente fragmento del Fray Gerundio, donde se menciona el método de aprendizaje del dómine Taranilla "aquel famoso dómine que atolondró a toda la Tierra de Campos con su latín crespo y enrevesado" y que fue uno de los referentes básicos de Zancas-Largas, futuro preceptor de Gerundio:

Como verbigracia aquella famosa carta con que examinaba a sus discípulos que comenzaba así: Palentiam mea si quis, que unos construían, si alguno mea a Palencia y, por cuanto esto no sonaba bien y parecía mala crianza con peligro de que se alborotasen los de La Puebla y no era verisímil que el dómine Taranilla - hombre, por otra parte, modesto, circunspecto y grande azotador - hablase con poco decoro de una ciudad, por tantos títulos tan respetable, otros discípulos suyos lo construían de este modo, si quis mea... - "Chico mío", suple fuge, "huye", Palentiam "de Palencia". A todos estos los azotaba irremisiblemente el impitoyable Taranilla; porque los primeros perdían el respeto a la ciudad y los segundos le empullaban a él sobre que, unos y otros, le suponían capaz de hacer un latín que, según su construcción, estaría atestado de solecismos. Hasta que, finalmente, después de haber enviado al rincón a todo el general porque ninguno daba con el recóndito sentido de la enfática cláusula, el dómine, sacando la caja, dando encima de ella dos golpecillos, tomando un polvo a pausas sorbido con mucha fuerza, arqueando las cejas, ahuecando la voz y hablando gangoso reposadamente, la construía de esta manera: "Mea, 've', si quis, 'si puedes', Palentiam, 'a Palencia'." Los muchachos se quedaban atónitos, mirándose los unos a los otros, pasmados de la profunda sabiduría de su dómine; porque, aunque es verdad que, echada bien la cuenta, había en su construcción, mitad por mitad, tantos disparates como palabras - puesto que ni meo, meas significa como quiera ir, sino ir por rodeos, por giros y serpenteando, ni queo, quis significa poder como quiera, sino poder con dificultad-, pero los pobres niños, no entendían estos primores; ni el penetrar la propiedad de los varios significados que corresponden a los verbos y a los nombres, que parecen sinónimos y no lo son, es para gramáticos de prima tonsura ni para preceptores de la legua. ${ }^{40}$

Tanto con el ingenio exuberante de la barroquización, como con la contaminación hispanizante, el objetivo pedagógico y educativo que se

${ }^{40}$ Isla 1995, pp. 240-241. 
buscaba era que el niño controlara con total profundidad la lengua latina, de forma que no hubiera ningún rasgo oscuro de ésta que se le escapara, así como estuviera preparado para realizar las redacciones y las composiciones más complejas que fueran posibles según la estética barroca a la que se subordinaban. Por eso, era importante recargar las reglas gramaticales y conocer nuevas estructuras sintácticas que desde el castellano enriquecieran la lengua latina con mayores posibilidades expresivas. A los "equivoquillos" citados a los que nos aludía Periquillo, se deben añadir la gran cantidad de modos compositivos oscuros, abigarrados, farragosos y crípticos que aprendió ya en la Escuela de Artes, recién entrado en los estudios superiores, y que son un claro reflejo del tipo de latín que se enseñaba. Precisamente, Lizardi, al igual que los "dómines" particulares, conocía muy bien la enseñanza superior de filosofía y el abstruso latín que los jesuitas empleaban, ya que las cursó en el jesuítico Colegio de San Ildefonso. Por lo tanto, prácticamente Lizardi habla en boca de Periquillo en el siguiente pasaje:

¡Pues qué tal sería yo de tenaz y tonto después que aprendí las reducciones, reduplicaciones, equipolencias y otras baratijas, especialmente ciertos desatinados versos, que os he de escribir solamente porque veáis a los que llegan los hombres por las letras! Leed, y admirad:

Barbara, Celarent, Darii, Ferio, Baralipton, Celantes, Dabitis, Fapesmo, Frisesomorum, Cesare, Camestres, Festino, Baroco, Darapti, Felapton, Disamis, Datisi, Bocardo, Ferison.

¡Qué tal! ¿No son estos versos estupendos? ¿No están más propios para adornar redomas de botica que para enseñar reglas solidas y provechosas? Pues, hijos míos, yo percibí inmediatamente el fruto de su invención; porque desatinaba con igual libertad por Bárbara que por Ferison, pues no producía más que barbaridades a cada palabra. Primero aprendí a hacer sofismas que a conocerlos y desvanecerlos; antes supe oscurecer la verdad que indagarla; efecto natural de las preocupaciones de las escuelas y de la pedantería de los muchachos.

En medio de tanta barahúnda de voces y terminajos exóticos, supe qué cosa eran silogismo, entimema, sorites y dilema. ${ }^{41}$ Este último es argumento

${ }^{41}$ Siguiendo este tipo de manuales, el dómine Don Supino también expone una buena lista de figuras de este estilo como son "catacresis, metalepsis, paroemias, enigmas, antífrasis, polysindetones, eufonías, antitetones”. Cf. Vegas y Quintano 1790, p. 130. 
terrible para muchos señores casados, porque lastima con dos cuernos, y por eso se llama bicornuto. ${ }^{42}$

Precisamente esos "sofismas", "barahúnda de voces y terminajos exóticos" son los medios de los que se valdrán los predicadores del Fray Gerundio para impartir discursos que (en boca de Fray Blas, uno de los personajes del libro) deben "agradar al auditorio, dar gusto a todos y caerles en gracia"; por eso tendrán "abundancia de doctrina", "multitud de citas" y "erudición", para satisfacer a los doctos; serán de "estilo pomposo, elevado, altisonante", para alegrar a los cultos; y la "popularidad" de los "refranes" y "cuentecillos encajados con oportunidad y dichos con gracia" darán gusto a los vulgares; y a todos alegrará "la presencia", el "despejo", la "voz" y las "acciones". ${ }^{43}$ Precisamente por este motivo, es importante abordar el problema que supone que un mal latín también corrompa a los ministros de la Iglesia que se encargan de educar en la fe y la moral al pueblo llano. Éste será el otro tema que Lizardi abordará inmediatamente en El Periquillo, y dirigirá esta vez su dedo acusador al estudio del Arte de Nebrija y los manuales de gramática que "mal aprendidos" desarrollaban el aprendizaje desviado de curas y seglares.

Es sabido que en 1599 se oficializa el Arte de Nebrija, según la versión del jesuita Juan Luis de la Cerda, como manual gramatical único para prácticamente toda España (de ahí que se le llame Arte Regio). A partir de ese momento, los jesuitas comienzan a publicar toda una serie de pequeños manuales (llamados comúnmente "platiquillas") que desarrollan y explican la obra de De la Cerda, según la óptica barroquizante e hispanizante que he detallado. De hecho había manuales que enseñaban la lengua latina a través de gran cantidad de figuras retóricas extravagantes que Lizardi calificaba de "terminajos exóticos". ${ }^{44}$ Por este motivo, tanto el Arte de Nebrija como sus "platiquillas" absorbían prácticamente toda la enseñanza

${ }^{42}$ Fernández de Lizardi 1962, pp. 36-37.

${ }^{43}$ Cf. Isla 1995 , p. 362.

${ }^{44}$ Manuales jesuíticos como el Gramático curioso (1678), de Pedro Miguel de Quintana, o la Elucidata Grammatica (1711), de Juan García de Vargas, dedicaban buena parte de sus manuales a explicar y ejemplificar estas figuras que entraban de lleno en el terreno de la emblemática (cf. Espino Martín 2008b, pp. 869-882), y las consideraban como instrumento indiscutible para el análisis y desarrollo de redacciones que se estructuraban en torno a una retórica ingeniosa y barroca (cf. Espino Martín 2011, en vías de publicación) que luego se presentaban públicamente en los Certámenes que, a su vez, publicitaban la calidad educativa de las escuelas de la Compañía. 
de la latinidad, y dejaban fuera del estudio a los autores clásicos que eran la fuente principal desde donde manaba el buen latín, además de que esta manera de enseñar daba preferencia a la lectura de breviarios, concilios y catecismos escritos en un latín ya degradado; de este modo muchos jóvenes eclesiásticos salían "tranquilos y satisfechos" en su latinidad por haber dado "cuatro manotadas" a "Lebrija" y, en materia de religión, "otras tantas al P. Lárraga". En definitiva, uno se podrá encontrar en un futuro a esos jóvenes "por esos pueblos de Dios", afirmando "lances de ignorancia escandalosos y aun increíbles", y desde los púlpitos diciendo: "sandeces y majaderías que no están escritas". ${ }^{45}$ Por ello, la mala enseñanza de la latinidad empieza por los profesores ignorantes, sigue con el uso de figuras retóricas exóticas y disparatadas, y termina con el uso de manuales gramaticales recargados de reglas que apartan el estudio de los autores clásicos y que fomentan el aprendizaje de textos complejos y farragosos en los que las reglas se aplican. Todo ello está enmarcado por un contexto tanto familiar como social, que por su propia ignorancia fomenta el atraso educativo y que a su vez aumenta el social, es decir, se vuelve un círculo vicioso sin fin.

En suma, a la corrupción social que la mala enseñanza de la latinidad acaba por abocar a los catrines y a los periquillos, se une la espiritual y moral de todos aquellos hombres de la Iglesia que se encargan de la "administración y custodia espiritual”, lo que refuerza todavía más la necesidad de la regeneración de la enseñanza que denuncia el autor mexicano.

\section{Conclusiones}

Hemos podido ver a lo largo del presente estudio cómo la sátira gramatical es una importante modalidad de la sátira para la crítica de una enseñanza deformada en una asignatura tan importante en siglos pasados como fue la lengua latina. Dicha modalidad tiene como ejes dos principios rectores: por un lado, la semblanza caricaturizada y deformada de la apariencia física y del comportamiento y modo del ser del profesor de latinidad (comúnmente llamado dómine) y, por otro lado, la crítica a su método educativo que se basaba en la enseñanza de un latín ignorante muy alejado de los presupuestos del latín canónico establecido por el estilo y la elegancia de los autores clásicos.

${ }^{45}$ Fernández de Lizardi, 1962, pp. 66-67. 
Al igual que la sátira en general, la sátira gramatical como modalidad de ésta, se podía emplear subordinada a otros géneros mayores como la narrativa, la lírica, o el teatro. En especial, la sátira se desarrolla por su naturaleza en la novela picaresca y es lo que sucede con las obras que aquí analizamos. La sátira gramatical ha sido empleada por motivos diversos, más o menos coincidentes, en autores como Quevedo (la presentación de una figura grotesca que muestre la degradación moral del ser humano), Espinel (la contraposición de un sistema educativo negativo frente a otro positivo) o Isla (la crítica a los enseñantes de los malos predicadores que perjudican el buen nombre de la Iglesia).

En el caso de las novelas de Lizardi tenían el objetivo de mostrarnos los peligros sociales que podía conllevar una mala educación. El autor mexicano tenía como único propósito mostrarnos que dentro de un sistema educativo degradado todo peldaño mal apuntalado contribuía a que se cayera todo el edificio social. Tanto Periquillo como Don Catrín muestran una vida perjudicada por una mala educación. Lizardi como burgués criollo participaba de una mentalidad ilustrada que pretendía reformar y modernizar su país. La aristocracia española a través de un tipo de educación perniciosa lograba que México se mantuviera encadenado a la decadencia económica, social y cultural que, a su vez, permitía una mayor facilidad para su dominio. Por este motivo, era necesario desligarse de las ataduras del Antiguo Régimen español a través de una nueva forma de enseñar y de nuevos métodos educativos. En todo ese engranaje de la educación, la sátira gramatical forma una parte esencial y relevante para que se mejore el panorama educativo, puesto que si se cambian los comportamientos y los métodos de los maestros y dómines que basan su enseñanza en el miedo y el castigo, así como en el aprendizaje de un latín absurdo y degradado, y se anteponen los derechos de los niños, así como se enseñan adecuadamente a los autores clásicos más puros y elegantes, se pondrá la primera piedra para el perfeccionamiento del sistema que a su vez podrá llevar a la sociedad a un mayor progreso y emanciparse definitivamente de las ataduras colonizadoras que la sometían a una oscuridad ignorante y subyugadora.

\section{BIBLIOGRAFÍA}

BAJTín, M., La cultura popular de la risa, Madrid, Alianza, $1998^{6}$. 
BEROUD, C., "La picaresca como única posibilidad literaria o el «Periquillo Sarniento»", en M. Criado del Val (ed.), Actas del I Congreso Internacional sobre la Picaresca, Madrid, Fundación Universitaria Española, pp. 1041-1045.

Calvo, Vicente, Grammatica proverbiandi. La enseñanza escolar del latín en la Baja Edad Media española: estudio y edición del texto contenido en el ms. 8950 de la Biblioteca Nacional, tomos I y II, tesis doctoral, Tomás González Rolán (dir.), Universidad Complutense, Madrid, 1995.

DíAz-PlajA, Guillermo, Antología mayor de la literatura hispanoamericana, vol. II, Barcelona, Labor, 1969.

EsPinel, Vicente, Vida del escudero Marcos de Obregón, edición, prólogo y notas de $\mathbf{M}^{\mathrm{a}}$. Soledad Urgoiti, Barcelona, Castalia, 2000.

EsPINO MARTín, Javier, "El humanismo docente: gramáticos y dómines en Luis Vives, Francisco de Quevedo, Jose Francisco de Isla y Manuel de Vegas y Quintano", en José María Maestre Maestre, Joaquín Pascual Barea, Luis Charlo Brea (eds.), Actas del III Congreso Internacional de Humanismo y pervivencia del mundo clásico. Homenaje al profesor Antonio Fontán, vol. III.5, AlcañizMadrid, Instituto de Estudios Humanísticos / CSIC, 2002, pp. 2457-2468.

_, "Racionalismo e Ilustración en la enseñanza del latín: evolución de las gramática escolapias en la segunda mitad del siglo XVIII", Cuadernos de Filología Clásica: Estudios Latinos, vol. 23.2, 2003, pp. 423-435.

_, Evolución de la enseñanza gramatical jesuítica en el contexto de los siglos XVI y primera mitad del XVIII, tesis doctoral, Francisco García Jurado (dir.), Madrid, Instituto de Estudios Humanísticos CSIC, Universidad Complutense de Madrid, 2007 (página web: <http://eprints.ucm.es/tesis/fll/ucm-t28425.pdf>).

_, "Panorama de la enseñanza gramatical de los Jesuitas españoles hasta su expulsión”, en José María Maestre, Joaquín Pacual Barea y Luis Charlo Brea (eds.), Actas del IV Congreso Internacional de Humanismo y Pervivencia del Mundo Clásico. Homenaje al profesor Antonio Prieto, tomo IV.2, AlcañizMadrid, 2008a, pp. 807-819.

_, "La influencia de la literatura emblemática en la gramática jesuítica latina en el siglo XVII", en César Chaparro, José Roso y Jesús Ureña (eds.), Paisajes emblemáticos: La construcción de la imagen simbólica en Europa y América, tomo II, Mérida, Editora Regional de Extremadura, 2008b, pp. 869-882.

_, “Enseñanza del latín e historia de las ideas: la revolución de Port-Royal y su repercusión en Francia y España durante el siglo XVIII", Minerva. Revista de Filología Clásica, 23, 2010a, pp. 261-284.

_, "El Dómine Don Supino de Manuel Vegas y Quintano y la controversia de la enseñanza del latín entre jesuitas e ilustrados a través de la sátira gramatical", $V$ Congreso Internacional de Humanismo y Pervivencia del Mundo Clásico. Homenaje al profesor Juan Gil, 2010b (actas en vías de publicación).

_. "La enseñanza gramatical al servicio de las propaganda religiosa contrarreformista: La 'retorización' de la gramática latina en el siglo XVII", XIII Congreso Español de Estudios Clásicos, 2011 (actas en vías de publicación). 
EsPIno Martín, Javier, Política y gramática en el siglo XVIII: Ilustrados contra jesuitas. Evolución de la enseñanza jesuítica del latín en el siglo XVIII español: la Corona de Castilla (1), Leipzig, EAE, 2012.

Fernández de Lizardi, José Joaquín, El Periquillo Sarniento, México, Porrúa, 1962 ("Sepan cuantos...", 1), 4 ed.

_, Don Catrín de la Fachenda-Noches tristes y día alegre, R. Oviedo, R. y A. Mejías (eds.), Madrid, Cátedra, 2001.

FRANCO, Jean, Historia de la literatura hispanoamericana, a partir de la independencia, Barcelona, Ariel, 1981.

García Jurado, Francisco y Javier Espino Martín, Dómines y pedantes. Enseñar latín en la literatura española, Leipzig, EAE, 2011.

GoIc, Cedomil, Historia y crítica de la literatura hispanoamericana, vol. I, Época colonial, Barcelona, Crítica, 1988.

GIL, Luis, "Gramáticos, humanistas y dómines", El Basilisco, 9, 1980, pp. 20-30.

GonzÁlez Echevarria R. y E. Pupo-Walker (eds), Historia de la literatura hispanoamericana, vol. I, Madrid, Gredos, 2006.

Isla, Francisco José de, Historia del famoso predicador Fray Gerundio de Campazas, alias Zotes, Enrique Rodríguez Cepeda (ed.), Madrid, Cátedra, 1995.

LAZO, Raimundo, Historia de la literatura hispanoamericana, vol. II, La Habana, Editorial Pueblo y Educación, 1974.

LEAL, Luis, "Pícaros y léperos en la narrativa mexicana", en M. Criado del Val (ed.), Actas del I Congreso Internacional sobre la Picaresca, Madrid, Fundación Universitaria Española, pp. 1033-1040.

LeChTE, John, 50 pensadores esenciales, Madrid, Cátedra Teorema, 1996.

MAdRIGAL, Luis Iñigo, "José Joaquín Fernández de Lizardi”, en L. I. Madrigal (ed.), Historia de la literatura hispanoamericana, vol. II, Madrid, Cátedra / Universidad Complutense, 1993.

Oviedo Pérez de Tudela, Rocío, “José Joaquín Fernández de Lizardi (17761827)", en Literatura hispanoamericana, textos y comentarios, vol. II, Madrid, Alhambra, 1986.

Quevedo, F., La vida del Buscón llamado Don Pablos, Domingo Ynduráin y F. Lázaro Carreter (eds.), Madrid, Cátedra, 1996.

Rabelais, F., Gargantúa, A. Yllera (ed.), Madrid, Cátedra, 2006.

Torres Villarroel, Diego de, Vida, M. M. Pérez López (ed.), Madrid, EspasaCalpe, 1989.

Van PraAg-Chantraine, Jacqueline, “«El Periquillo Sarniento»: un pícaro criollo", en M. Criado del Val (ed.), Actas del I Congreso Internacional sobre la Picaresca, Madrid, Fundación Universitaria Española, pp. 1047-1054.

Vegas y Quintano, Manuel, Gramática y conducta del dómine Don Supino, discípulo del dómine Mazorrales, y la que expresa su crítico preguntador, Alcalá de Henares, Imprenta de D. Joseph Antonio Ibarrola, 1790.

VIVES, Luis, Diálogos sobre la educación, traducción, introducción y notas de P. Rodríguez Santidrián, Madrid, Alianza Editorial, 1987. 